\title{
Filling jobs by special initiative Richard Pearson*
}

\author{
The UK Government has boasted of success in encouraging the sunrise \\ industries. Will the manpower be there to support growth?
}

JOB prospects in science and technology are in a period of rapid change. While new "discoveries" are one major driving force, their application to society's needs and a changing financial context are nowadays equally strong pressures affecting employment. Existing staff need new skills, some have to retrain, while new jobs and areas of employment are always emerging. In the United States, skill shortages in information technology (IT) and electronics have led to severe depletion in the education system of the teachers needed to educate and train future specialists.

In the United Kingdom, cutbacks in the university system in the past 3 years have led many universities to rely on natural wastage to reduce staff numbers. Not surprisingly, those with marketable skills in industry have often been the ones to leave, while the rash of early retirements and freezes on recruitment have led to unbalanced staffing structures and blocked career streams. In an effort to unblock the system, a "new blood" initiative was announced by the Department of Education and Science in late 1982 which enabled the universities to recruit more than 240 new, young, teaching and research staff. There were also funds for a further 70 staff in IT as part of a wider "IT initiative" to increase the supply of graduates coming onto the labour market. Initial evaluations of these two schemes are now available.

Altogether, more than 300 posts were created in the universities and 87 per cent of them had been filled by late 1983 . The University Grants Committee (UGC) reported a wide variation in the number and quality of applications for individual posts. The number of applications was as high as 80 for some posts in medicine with many strong candidates, and as low as 4 in engineering. The highest quality was found in applicants in the biological sciences and mathematics, the lowest in engineering. Information technology had the lowest number of applicants per post. Not surprisingly, the posts in engineering and information technology were hardest to fill, with nearly one in five of the information technology posts, and one in three in engineering remaining vacant (see table).

The aim of attracting young staff was largely achieved; more than half the recruits were under 30 , and more than 90 per cent under the recommended age limit of 35. Interestingly, one in ten of the infor-

- Institute of Manpower Studies, Mantell Building. University of Sussex, Brighton BN1 9RF, UK.

\begin{tabular}{lccc}
\hline \multicolumn{4}{c}{ New posts in UGC new blood and IT initiative } \\
\hline Subject & Posts in & Applications per & Posts unfilled at \\
& 1983 & post & 30 Nov.1983 \\
Medicine & 43 & 19.7 & 5 \\
Engineering & 48 & 15.9 & 15 \\
Biological sciences & 25 & 32.1 & 3 \\
Maths/ & & & 1 \\
physical sciences & 86 & 27.3 & 2 \\
Agricultural/veterinary science & 8 & 13.7 & 4 \\
Arts/social studies & 32 & 27.5 & 13 \\
Information technology & 70 & 10.9 & 43 \\
Total & 312 & 20.8 & \\
\hline
\end{tabular}

mation technology recruits was over 36 , while three were under 25 . In a year dedicated to "Women in Science and Engineering", none of the information technology posts and only one of the engineering posts was filled by a woman, although more were appointed in medicine (6) and the sciences (9).

The IT initiative of 1982 also included additional funds for research and student places, as well as for a series of one year postgraduate and post-experience courses to increase the supply of people with IT skills. An initial evaluation of the first year of these courses, sponsored by the Science and Engineering Research Council (SERC), shows them to be making a rapid contribution to meeting recruitment needs despite their newness and a relatively low level of awareness by employers (Manpower for Information Technology, A. Gordon and R. Pearson, IMS). SERC is supporting two types of course, "conversion" courses aimed at graduates with no previous experience of information technology and "specialist" courses for information technology graduates.

Although many of the courses, run in both universities and polytechnics, were announced only a few months before they began in October 1982, there was a great deal of interest among first degree graduates - some course organizers received more than 300 applications for 20 or 30 places. Much of this enthusiasm was no doubt prompted by the poor job prospects for graduates without skills in information technology. Although there was a significant number of women applicants, they represented only one in eight students, possibly because many of the successful applicants had first degrees in engineering or physical science, often an essential entry requirement. The students themselves had mixed backgrounds; one in four were from polytechnics, and one in four had non-

technical first degrees. Their ages ranged from 21 to 55 , half were over 25 and officially classified as "mature" students.

The numbers graduating so far, fewer than 200 , were relatively low when compared with the expected 1,000 graduates in 1984. In 1983 there was little awareness among employers of this new source of skilled information technology manpower. Most employers were seeking a broad based intake of first degree graduates and it was rare to find a significant discrete demand for MSc or diploma students in any of the information technology subjects. Some were, however, sought in communications and control engineering. In the case of postgraduates with first degrees in the arts, some employers doubted whether they could learn enough useful computing in one year to be worthwhile, although one major electronics company has recently organized his own three-month courses to turn arts graduates into successful realtime programmers. By the time they graduated, most students had found jobs that used their new skills, with banks and in education as well as in the information technology industry. Starting salaries ranged from $£ 5,000$ to more than $£ 12,000$ a year, with half in the $£ 7,000-8,000$ range, well above the average starting salary for new graduates, which in 1983 was just over $£ 6,000$.

The information technology initiative has been successful so far in creating a new supply of skills. Ironically it could be poor information that constrains this supply of information technology skills in the future, with some employers unaware of these new types of graduates, and some course organizers having little interest in ascertaining industry's needs. Women still remain a large untapped source of recruits for the courses and for industry. This always assumes of course that there will be enough teaching staff to run the courses. $\square$ 